\title{
Relation between walking speed and muscle strength is affected by somatosensory loss in multiple sclerosis
}

\author{
P Thoumie, E Mevellec
}

J Neurol Neurosurg Psychiatry 2002;73:313-315

Objective: To evaluate the correlation between gait speed and strength in multiple sclerosis (MS) with particular regard to patients presenting with proprioceptive loss.

Methods: Gait evaluation and isokinetic testing of muscular function were performed in 20 patients with unaided gait (expanded disability status scale $<6$ ). Patients were separated into two groups in relation to the occurrence of somatosensory involvement: pyramidal group (8 patients) and sensory-pyramidal group (12 patients). Ten healthy subjects of similar age, sex, and height constituted a control group to evaluate gait parameters.

Results: In the whole patient group, gait speed was reduced and strongly related to hamstring peak torque but not with quadriceps peak torque. The gait speed and peak torques of quadriceps and hamstrings were similar in both groups of patients. However, in the patients with proprioceptive loss there was both a strong correlation between gait speed and hamstring torque and a significant correlation with quadriceps torque. In the pyramidal group there was poor or no correlation.

Conclusion: In patients with undifferentiated MS there is some correlation between gait speed and muscle strength. In the case of sensory loss, a higher contribution of both flexor and extensors of the lower limbs was observed, suggesting that muscular compensation occurred in this situation to maintain gait speed. These results are relevant to assess rehabilitation modalities in MS.

Q uantitative data from both gait parameters and muscular strength have dramatically changed the conception of rehabilitation in patients suffering central nervous system lesions. Following stroke, a relation has been reported between muscular strength and gait speed, ${ }^{12}$ underlining the value of muscular reinforcement in this situation. Similar results can be expected in multiple sclerosis (MS), although results from studies focusing on gait changes following rehabilitation have been contradictory, which may be related to variability in clinical features. Somatosensory deficit is a common feature in MS and contributes to disability as assessed by the expanded disability status scale (EDSS). Recent studies focused on the compensatory mechanisms that can occur following this sensory deficiency in relation to balance control, ${ }^{4}$ although the direct contribution of motor function to compensation during gait has not been evaluated. This study aimed firstly at evaluating the correlation between muscular strength and gait speed in MS and secondly at elucidating whether proprioceptive loss modifies this relation.

\section{MATERIALS AND METHODS}

The participants in this study were ambulatory patients with MS diagnosed according to the Poser criteria. Inclusion criteria were clinical features of pyramidal track and the ability to walk a distance of at least $100 \mathrm{~m}$ unaided (EDSS < 6). Exclusion criteria were cerebellar or visual involvement and a high level spasticity (Ashworth 3 or 4). Twenty patients participated in the experiment: 13 men and 7 women, average (SD) age 42 (14) (range 24-61). Somatosensory involvement was defined by a decrease in vibration perception or joint sense in at least one lower limb. Eight patients with MS with isolated pyramidal signs were selected (pyramidal group) and 12 with pyramidal signs and associated somatosensory deficit (sensory-pyramidal group).

Gait was evaluated using Bessou's locometer. ${ }^{5}$ Two recordings were made, at a comfortable speed and then at maximal speed on a $6 \mathrm{~m}$ runway. Gait speed was the only parameter considered in this study.

Muscle strength was assessed during an isokinetic test of knee flexion and extension with a Cybex Norm dynamometer (Znetix, Bainbridge Island, Washington, USA). Patients were tested in sitting position with $110^{\circ}$ of hip flexion. Gravity was corrected for before the measurements to account for the weight of the limb. Before the test, a warmup of 10 submaximal repetitions was performed to allow patients to familiarise themselves with the device. Then muscle strength was measured at slow speed $\left(60^{\circ} / \mathrm{s}\right)$ as proposed by Joubrel et al. ${ }^{6}$ All tests consisted of five repetitions of flexion and extension of both knees to assess maximal peak torque parameters. Four values were considered in each patient, corresponding to minimal and maximal quadriceps and hamstring peak torques - that is, values of the more and the less affected sides.

\section{Data analysis}

Data of pyramidal and sensory-pyramidal group patients were compared by post hoc Bonferroni's test. Correlation between strength (minimal and maximal quadriceps and hamstring peak torques) and gait speed were assessed using the Pearson coefficient and analysed in subgroups. For statistical analysis, StatView version 5 (SAS Institute, Cary, North Carolina, USA) was used. All data were analysed with a 0.05 level of significance and are presented as mean (SD).

\section{RESULTS}

The two groups were similar in age, sex, and height. A reduction of gait speed was observed in both patient groups relative to control subjects, both at comfortable speed $(2.56(0.22)$ and $2.75(0.18) \vee 4.2(0.7) \mathrm{km} / \mathrm{h})$ and at maximal speed $(4.26$ $(0.89)$ and $4.48(1.22) v 6.6(1.2) \mathrm{km} / \mathrm{h})$. No significant difference was observed between the two patient groups in gait and strength parameters (table 1 ).

Table 2 summarises the correlation analysis. For all patients with MS, a significant correlation was observed between hamstring strength and gait speed $(r=0.61$ and $r=0.55$,

Abbreviations: EDSS, expanded disability status scale; MS, multiple sclerosis 
Table 1 Strength and gait parameters in subgroups of patients with multiple sclerosis

\begin{tabular}{|c|c|c|c|c|c|c|}
\hline & \multicolumn{2}{|c|}{ Quadriceps peak torque $(\mathrm{nm})$} & \multicolumn{2}{|c|}{ Hamstring peak torque $(\mathrm{nm})$} & \multicolumn{2}{|c|}{ Gait speed $(\mathrm{km} / \mathrm{h})$} \\
\hline & Minimal & Maximal & Minimal & Maximal & Comfortable & Maximal \\
\hline Pyramidal group ( $n=8$ ) & $73(30)$ & $99(37)$ & $18(17)$ & 37 (19) & $2.56(0.22)$ & $4.26(0.89)$ \\
\hline Sensory-pyramidal group $(n=12)$ & $72(27)$ & $90(34)$ & $25(10)$ & $40(13)$ & $2.78(0.18)$ & $4.48(1.22)$ \\
\hline
\end{tabular}

Table 2 Correlation matrix between gait and strength parameters

\begin{tabular}{|c|c|c|c|c|c|c|c|c|}
\hline & \multicolumn{2}{|c|}{$\begin{array}{l}\text { Minimal hamstring } \\
\text { peak torque }\end{array}$} & \multicolumn{2}{|c|}{$\begin{array}{l}\text { Maximal hamstring peak } \\
\text { torque }\end{array}$} & \multicolumn{2}{|c|}{$\begin{array}{l}\text { Minimal quadriceps peak } \\
\text { torque }\end{array}$} & \multicolumn{2}{|c|}{$\begin{array}{l}\text { Maximal quadriceps } \\
\text { peak torque }\end{array}$} \\
\hline & $\begin{array}{l}\text { Comfortable } \\
\text { speed }\end{array}$ & $\begin{array}{l}\text { Maximal } \\
\text { speed }\end{array}$ & $\begin{array}{l}\text { Comfortable } \\
\text { speed }\end{array}$ & $\begin{array}{l}\text { Maximal } \\
\text { speed }\end{array}$ & $\begin{array}{l}\text { Comfortable } \\
\text { speed }\end{array}$ & $\begin{array}{l}\text { Maximal } \\
\text { speed }\end{array}$ & $\begin{array}{l}\text { Comfortable } \\
\text { speed }\end{array}$ & $\begin{array}{l}\text { Maximal } \\
\text { speed }\end{array}$ \\
\hline All patients $(n=20)$ & $0.61^{* *}$ & $0.55^{* *}$ & 0.40 & 0.24 & 0.34 & $0.44^{*}$ & 0.28 & 0.34 \\
\hline Pyramidal subgroup $(\mathrm{n}=8$ ) & 0.47 & 0.51 & 0.45 & 0.52 & -0.10 & 0.18 & -0.12 & 0.13 \\
\hline Sensory-pyramidal subgroup $(n=12)$ & 0.76 ** & $0.64^{*}$ & 0.35 & 0.07 & $0.66^{*}$ & $0.59 *$ & $0.59 *$ & 0.48 \\
\hline
\end{tabular}

$\mathrm{p}=0.01$, at comfortable and maximal speeds, respectively) and to a lesser degree between quadriceps strength and maximal speed $(r=0.44, \mathrm{p}=0.05)$. In the pyramidal group, a correlation was observed between hamstring strength and gait speed but not to any significant level. No correlation was observed with quadriceps peak torque. In the sensorypyramidal group, a high correlation was observed between hamstring strength and both comfortable speed $(r=0.76$, $\mathrm{p}<0.01)$ and maximal speed $(r=0.64, \mathrm{p}=0.05)$. Moreover, a significant correlation between quadriceps strength and gait speed was observed ( $r=0.66$ for minimal quadriceps strength and comfortable speed and $r=0.59$ for both minimal and maximal quadriceps strength and both maximal and comfortable speed, $\mathrm{p}<0.05)$.

\section{DISCUSSION}

When considering the results of the patients with undifferentiated MS, gait speed was related mainly to hamstring strength both at comfortable and at maximal speeds. This is in line with the findings of Olney et $a l^{2}$ that, in hemiplegic patients, flexor muscle weakness (at the knee, hip or ankle level) was related more to a gait limitation than to extensor strength. In our study, a weak correlation was observed between gait and quadriceps strength, in contrast to Bohannon's findings in hemiplegic patients. ${ }^{1}$ This may be related to the moderate strength reduction observed in our patients, who were selected for their ability to walk $100 \mathrm{~m}$ unaided, while patients included in other studies were more affected and were allowed to use a cane.

The main point we have to consider is that this relation in MS can change depending on the clinical features.

In patients with sensory loss, the relation between gait and strength parameters is significant and would not be obvious when considering only the results of the whole group. Postural consequences of somatosensory involvement are gait limitations following complete sensory loss, with a subjective feeling of instability and an increased incidence of falls. Many mechanisms of compensation can occur in these conditions and visual, vestibular, and tactile compensation has been studied in balance control. ${ }^{4}$ Only a few studies have focused on compensation during locomotion. In animals, Grillner ${ }^{7}$ used experimental deafferentation in cats that induced a prolonged stance on the contralateral limb during automatic locomotion. In an experimental paradigm involving the balance recovery process in humans, ${ }^{8}$ it has been established that patients with experimental deafferentation following ischaemia of one leg reduced the activity of the ipsilateral leg and increased the activity of the contralateral leg to avoid a lowered centre of gravity. In clinical situations, somatosensory effects on gait have been studied mainly in diabetic patients with neuropathy, walking with shorter stride lengths and increased double support. ${ }^{9}$

We can therefore consider that these results present an argument for motor compensation for sensory loss since these patients are more dependent than control patients on decreased strength. The clinical relevance of these results can be stressed in the field of rehabilitation when further studies are needed to explain its exact mechanism. From a general point of view, maintenance or reinforcement of hamstring strength appears to be a logical goal regardless of the clinical form. The fact that somatosensory loss contributes to increased dependence on strength involvement may lead us to consider that more systematic strengthening must be proposed in this situation in addition to postural training.

In the future, it seems to be important to consider clinical features in the evaluation of rehabilitation procedures in MS. It was recently underlined that average walking speed may be a better parameter than maximum walking distance to evaluate disability in $\mathrm{MS}^{10}$ We may now consider that, besides inclusion in rehabilitation protocols according to EDSS, a specific study within clinical subgroups has to be done to consider the modalities of MS rehabilitation and its ability to improve gait parameters.

\section{Authors' affiliations \\ P Thoumie, E Mevellec, Service de Rééducation Neuro-Orthopédique, Inserm U 483, Hôpital Rothschild, 33 boulevard de Picpus, F-75012 Paris, France \\ Competing interests: none declared}

Correspondence to: Dr P Thoumie; philippe.thoumie@rth.ap-hop-paris.fr

Received 4 February 2002

Accepted 23 April 2002

\section{REFERENCES}

1 Bohannon RW, Andrews AW. Correlation of knee extensor muscle torque and spasticity with gait speed in patients with stroke. Arch Phys Med Rehabil 1990,71:330-3.

2 Olney SJ, Griffin MP, McBride ID. Temporal, kinematic and kinetics variables related to gait speed in subjects with hemiplegia: a regression approach. Phys Ther 1994,74:872-85. 
3 Gehlsen G, Beekman K, Assmann N, et al. Gait characteristics in multiple sclerosis: progressive changes and effects of exercise on parameters. Arch Phys Med Rehabil 1986,67:536-9.

4 Horak FB. Postural ataxia related to somatosensory loss. Adv Neurol 2001,87:173-82.

5 Bessou P, Dupui P, Montoya R, et al. Simultaneous recording of longitudinal displacements of both feet during human walking. J Physiol 1989,83:102-10.

6 Joubrel I, Nicolas B, Robineau S, et al. Evaluation isocinétique de la flexion-extension de genou chez les patients ambulatoires atteints de sclérose en plaques. Ann Réadapt Med Phys 2000,43:138-45.
7 Grillner S. Locomotion in vertebrates: central mechanisms and reflex interactions. Physiol Rev 1975,55:247-304.

8 Thoumie P, Do MC. Changes in motor activity and biomechanics during balance recovery following cutaneous and muscular deafferentation. Exp Brain Res 1996, 110:289-97.

9 Courtemanche $\mathbf{R}$, Teadsale N, Boucher $\mathrm{P}$, et al. Gait problems in diabetic neuropathic patients. Arch Phys Med Rehabil 1996,77:849-55. 10 Albrecht H, Wotzel C, Erasmus LP, et al. Day-to-day variability of maximum walking distance in MS patients can mislead to relevant changes in the expanded disability status scale (EDSS): average walking speed is a more constant parameter. Mult Scler 2001,7:105-9.

\section{NEUROLOGICAL STAMP}

\section{Cécile Vogt (1875-1962)}

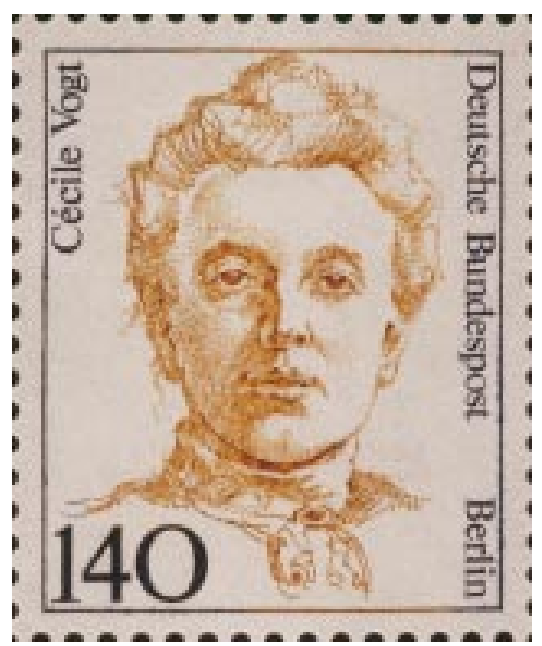

écile Vogt was French and her husband Oskar Vogt (1870-1959) half Danish and half German. She married Oskar in 1899 in Berlin. The Vogts crusaded for a brain institute and finally the Kaiser Wilhelm Institute für Hirnfirschung was created for them in Berlin. Famous neurologists such as Brodman and Bielschowsky did research there, Brodman making his main contributions while working at the institute.

The Vogts studied the layered structure of the cerebral cortex, cerebral fibre pathways, and the anatomical and physiological aspects of the extrapyramidal system. They refined and defined what was known of the cortical areas. The Vogts were among the investigators who described the pathological lesions of Huntington's chorea. Cécile and Oskar Vogt confirmed that this was caused by asphyxia neonatorum.

After Vladimir Lenin, the intellectual leader of the Russian revolution, died in 1924 at the age of 54 from progressive cerebrovascular disease, the Soviet government asked Oskar Vogt to examine his brain. Vogt found that pyramidal neurones in layer 111 in several areas of Lenin's cerebral cortex were exceptionally large and numerous. Based on his opinion that these cells might subserve "associated thinking", Vogt apparently believed that this structural peculiarity could account for the acute and penetrating mental processes that characterised Lenin's personality-the implication being that it was possible to detect the material substrate of genius.

After Oskar's death, Cécile moved to England, spending her later years with her daughter. There has not been a stamp of Oskar Vogt, but Cécile was portrayed in a series issued between 1986 and 1991 portraying famous women (Stanley Gibbons 2160, Scott 1487).

L F Haas 